\title{
Research on evaluation index system of information system equipment system contribution rate
}

\author{
Jian $\mathrm{Hou}^{1, *}$, Ruihua Wang ${ }^{2}$, Jiajia $\mathrm{Wang}^{1}$, and Zhou Yang ${ }^{2}$ \\ ${ }^{1}$ Beijing Jinghang Research Institute of Computing and Communication, Beijing, China \\ ${ }^{2}$ PLA Academy of Military Science, Beijing, China
}

\begin{abstract}
The construction of index system is the basis of equipment system contribution rate evaluation, and is also one of the main contents of equipment test and appraisal. This paper discusses the concept of systems contribution rate, introduces the evaluation process of system contribution rate of information system equipment, and gives the construction principles and ideas of information system equipment system contribution rate evaluation index system. Then, referring to the theory of operational loop, the evaluation index system of system contribution rate is given from the perspectives of system capability and system effectiveness. The evaluation index of this paper can provide decision support for the development of equipment planning system.
\end{abstract}

\section{Introduction}

The rapid development of information technology has not only promoted the industrial revolution, but also led to the military revolution, making profound changes in military technology, weapons and equipment, mode of operation, form of war, military regulations and troop composition. Information, information system, information platform, weapon and ammunition become the main battle weapon on the battlefield ${ }^{[1]}$. Information system equipment becomes the binder and multiplier for the formation of system combat capability. System combat capability based on information system has become the basic form of combat effectiveness. The test identification and evaluation of information system equipment should run through the whole life cycle of weapons and equipment, and provide the main basis for the decision-making in various stages of equipment demonstration, development, finalization and use ${ }^{[2]}$. At present, most of the project approval evaluation of new information system equipment adopts qualitative method or evaluates the capability of single equipment and single system, and the impact evaluation of new equipment on the whole system has not been carried out, so it is urgent to find out the "base number" of information system equipment through the evaluation of system contribution rate ${ }^{[3,4]}$. The evaluation index of system contribution rate is a specific form to reflect the contribution ability of information system equipment to the system. It is the basis of establishing the

\footnotetext{
*Corresponding author: houjhouj@163.com
} 
evaluation model of system contribution rate and an important task in the evaluation of weapon equipment effectiveness. Therefore, it is very important to study the evaluation index system of system contribution rate.

\section{Overview of system contribution rate evaluation}

In the military field, system contribution rate is a new concept, and there is no clear and unified definition. $\mathrm{Li}$ Jichao and Yang Kewei of National University of Defense Technology defined the contribution rate of equipment as follows: The contribution rate of equipment refers to the value of the capability or operational effect of a specific type of equipment to complete the combat mission under the included equipment system and given combat conditions ${ }^{[5]}$. Based on the Santa fe institute CAS (Complex Adaptive System) System operation view, can think: equipment System contribution is tries to evaluate equipment into direct task operating System (the System) or combined operations System (System), after System operational effectiveness and combat ability than does not contain to assess equipment System of combat effectiveness and the ability to change degree ${ }^{[6,7]}$.

\section{System contribution rate evaluation framework}

The perspective of system contribution rate evaluation determines the different evaluation methods of system contribution rate. At present, the system contribution rate of information system equipment is mainly evaluated from the perspectives of architecture, system operational capability and system operational effectiveness. The connotations of the three operational perspectives is shown in table $1^{[8]}$.

Table 1. Connotation of system contribution rate from different evaluation perspectives

\begin{tabular}{|c|c|c|}
\hline Serial & perspective & connotation \\
\hline 1 & $\begin{array}{c}\text { Operational capability } \\
\text { perspective }\end{array}$ & $\begin{array}{c}\text { Contribution to the improvement of system combat } \\
\text { capability, static perspective }\end{array}$ \\
\hline 2 & $\begin{array}{c}\text { Operational } \\
\text { effectiveness perspective }\end{array}$ & $\begin{array}{c}\text { Measurement of the degree to which a system } \\
\text { completes a given task. Dynamic perspective }\end{array}$ \\
\hline 3 & $\begin{array}{c}\text { architecture optimization } \\
\text { perspective }\end{array}$ & $\begin{array}{c}\text { The contribution made by making up the defect of } \\
\text { equipment architecture }\end{array}$ \\
\hline
\end{tabular}

The combat capability of the equipment system refers to the capability or potential of the equipment system to accomplish certain combat tasks. It is a relatively static concept. The contribution of equipment to system combat capability is mainly reflected in the improvement of system combat capability. The existing evaluation methods for the capability contribution rate of equipment systems have the advantage that the evaluation indexes are easy to obtain and easy to be understood by the combat commanders and equipment managers and used to guide the practice. However, the existing methods cannot reflect the emerging capability of equipment system ${ }^{[9]}$ :

The combat effectiveness of the equipment system refers to the effectiveness of the equipment system to achieve specific mission objectives. It is a relatively dynamic concept, and the contribution of equipment to the combat effectiveness of the system is mainly reflected in the performance of the combat effectiveness of the system ${ }^{[10]}$. The evaluation of operational effectiveness contribution rate of equipment system can predict or test the contribution of equipment to the effectiveness of the system in realizing operational mission objectives under specific conditions, thus providing a theoretical basis for the inspection and optimization of operational plans. When evaluating the efficiency contribution rate of the equipment system, the index system constructed includes both qualitative and quantitative indexes, and even fuzzy indexes combining qualitative and 
quantitative indexes. How to quantify the evaluation index has become the key to the evaluation of system contribution rate.

Equipment architecture refers to the various equipment systems that constitute the equipment system and their interrelation. The contribution of equipment to the architecture is mainly reflected in the optimization of the architecture ${ }^{[11]}$. The existing research on evaluation of contribution rate of equipment architecture mainly focuses on the decomposition and construction of evaluation index, but there is no consensus on the specific content of evaluation index system of contribution rate of equipment architecture.

The evaluation steps of information system equipment system contribution rate are as follows:

Step 1: Define combat tasks, decompose specific tasks to obtain corresponding capability requirements;

Step 2: Build the information system equipment system combat network, and calculate the combat capability of the system based on the combat ring;

Step 3: Remove the red equipment in the combat network one by one, and calculate the combat capability of the combat network of the equipment system after each equipment is removed;

Step 4: Consider the equipment cost factor and calculate the system contribution rate of information system equipment.

\section{Construction of system contribution rate evaluation index system}

\section{1 operation loop}

Combat loop[15] was proposed by Professor Tan Yuejin based on observation-orientationDecesion-Action (OODA) cycle theory[16-17]. It refers to the closed loop formed by reconnaissance equipment, decision-making equipment and strike equipment, etc. with enemy targets in order to complete specific combat tasks [18-19]. In general, fighting ring the interaction relationship between the equipment include: reconnaissance, decisionmaking, command, hit the four kinds of relationship, as information war complexity has increased, the interaction relationship between the equipment include: reconnaissance equipment relationship exists between information sharing and decision-making equipment between collaborative relationship command, fighting ring diagram as shown in Fig. 1.

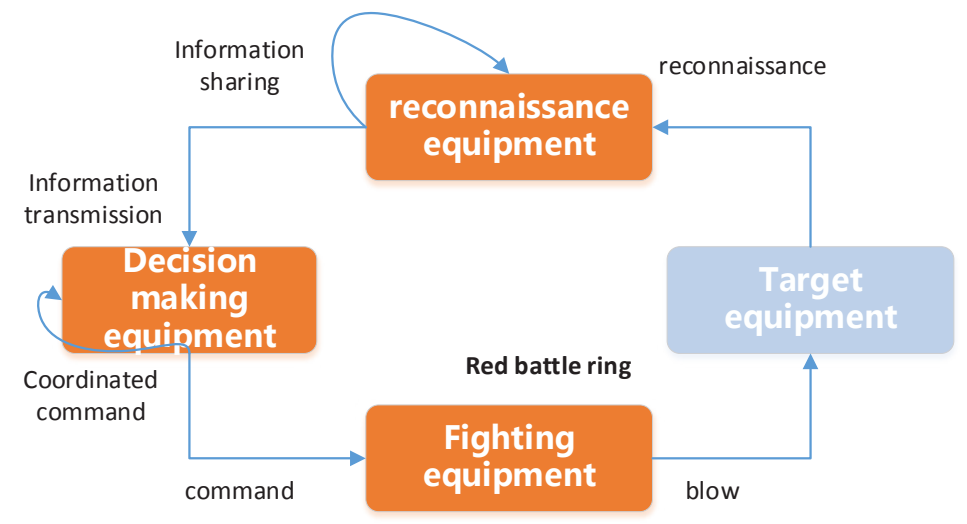

Fig. 1. Diagram of operational loop. 


\subsection{Index system construction}

\subsubsection{Evaluation index system construction method}

The establishment of evaluation index system based on the tree decomposition method of key combat issues includes the following two steps.

The first step is to identify mission-level issues. The mission level issue is the Critical Operational Issue (COI). Key operational questions are high-level questions that acquisition departments answer through system testing and evaluation based on mission requirements. Before determining the evaluation indicators and test contents, the key operational issues must be determined first. First, the key operational issues that need to be solved in the operational tests must be determined. The second is to use tree analysis technology to decompose the key operational problems and determine the specific content of operational tests.

The second step is to use tree analysis technology to decompose key operational issues and determine specific operational test items. The tree analysis technique is an effective way to determine operational effectiveness and operational applicability and to assess actual data requirements and operational test measurements. To adopt this method, the key operational problems should be decomposed into operational test targets, effectiveness measures, performance measures and data requirements in a tree structure step by step, and the solution of each key problem should be achieved through the identification of some operational test criteria. A measure of effectiveness as a direct contribution to an objective can be traced, through which it can be identified as a direct contribution to solving one or more key operational problems.

\subsubsection{The basic process of evaluation index system construction}

The system contribution rate index system is constructed by analyzing key operational issues. The basic process is shown in Fig. 2 below

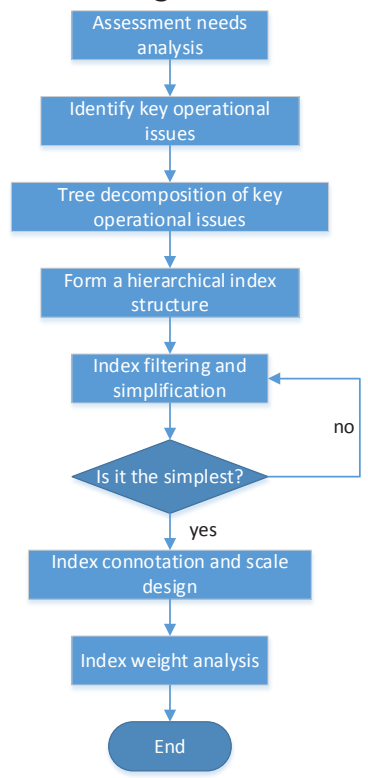

Fig. 2. Construction process of the evaluation index system of system contribution rate. 


\subsubsection{Construction of evaluation index system}

To study the system contribution rate of information system equipment, it is necessary to construct the evaluation index system of system contribution rate of equipment. The evaluation index system of system contribution rate in this paper contains two first-level capability indexes, namely, system capacity contribution rate and system efficiency contribution rate. The composition of the evaluation index system is shown in Table 2. The contribution of equipment to the capability of the system refers to the contribution of the equipment system to the formation of new qualitative capabilities, the filling of weak points and the improvement of existing capabilities. The contribution rate of equipment to system effectiveness refers to the contribution of equipment system to improving the completion degree of combat tasks and reducing combat loss under typical combat scenarios. Among them, the index system of system capability contribution rate includes three secondary capability indexes: information support ability, command decision-making ability and firepower strike ability. The index system of system efficiency contribution rate consists of four three-level indexes: reconnaissance, detection, judgment, decision evaluation and action.

Table 2. Evaluation index system of information system equipment system contribution rate

\begin{tabular}{|c|c|c|c|}
\hline & First level & second level & third level \\
\hline \multirow{20}{*}{$\begin{array}{l}\text { System } \\
\text { contribution rate }\end{array}$} & \multirow{10}{*}{$\begin{array}{l}\text { System capacity } \\
\text { contribution rate }\end{array}$} & \multirow{4}{*}{$\begin{array}{l}\text { Information support } \\
\text { capacity }\end{array}$} & $\begin{array}{l}\text { Intelligence and reconnaissance } \\
\text { capability }\end{array}$ \\
\hline & & & Information transmission capability \\
\hline & & & Information processing capacity \\
\hline & & & Information sharing capability \\
\hline & & \multirow{3}{*}{$\begin{array}{c}\text { Command decision } \\
\text { ability }\end{array}$} & assist decision making ability \\
\hline & & & $\begin{array}{c}\text { Comprehensive charge coordination } \\
\text { ability }\end{array}$ \\
\hline & & & Fire coordination support capability \\
\hline & & \multirow{3}{*}{$\begin{array}{l}\text { Firepower striking } \\
\text { capability }\end{array}$} & Fire damage capability \\
\hline & & & Electronic jamming capability \\
\hline & & & Precision strike capability \\
\hline & \multirow{10}{*}{$\begin{array}{c}\text { System } \\
\text { efficiency } \\
\text { contribution rate }\end{array}$} & \multirow{3}{*}{$\begin{array}{l}\text { Reconnaissance } \\
\text { detection }\end{array}$} & Reconnaissance detection speed \\
\hline & & & Reconnaissance detection probability \\
\hline & & & False alarm rate \\
\hline & & \multirow{2}{*}{ Judge } & IFF probability \\
\hline & & & Target fusion probability \\
\hline & & \multirow{2}{*}{ Decision evaluation } & Identification speed \\
\hline & & & Target assignment speed \\
\hline & & \multirow{3}{*}{ Operational } & launch preparation time \\
\hline & & & accuracy \\
\hline & & & Effective strike rate \\
\hline
\end{tabular}

\section{5 conclusion}

Starting from the connotation of system contribution and the mission of information system equipment, this paper comprehensively considers the actual situation of specific combat background, combat mission. From the perspective of system capability contribution rate and system efficiency contribution rate, the evaluation index system of information system equipment system contribution rate is constructed, which can effectively target the evaluation of equipment in multi-task and multi-scene. In the next step, the detailed equipment indicators and the new generation of information technologies such as artificial 
intelligence will be taken into consideration to optimize the evaluation model, so as to make the evaluation of contribution rate more accurate and provide decision support for the actual equipment development.

\section{References}

1. Z. P. Tong, Integrated Electronic Information System (SECOND edition) [M]. Beijing: National Defense Industry Press, (2010)

2. T. Zhen, Operational Effectiveness Evaluation Method of Surface-to-surface missile weapons [M]. Beijing: National Defense Industry Press, (2005)

3. R. Jun, X. F. Hu, Z. Feng, Effectiveness prediction of weapon equipment system-ofsystems based on deep learning feature transfer[J]. Systems Engineering and Electronics, (2017)

4. M. Du, Z. Cheng, X. Shi. Contribution Rate Evaluation of Army Air Defence Brigade Equipment System Based on Vector Model[J]. Journal of Physics: Conference Series, (2020)

5. J. C. Li, K. W. Yang, X. K. Zhang, et al. Equipment Contribution Degree Evaluation Method Based on Combat Network of Weapon System-of-Systems[J]. Complex Systems and Complexity ence, (2016)

6. X. M. Luo, Y. L. Zhu, R. He. Evaluation of Contribution for Equipment Operational Test System Based on Complex Adaptive System[J]. Journal of Academy of Armored Force Engineering, (2015)

7. P. K. Davis, Analytic Architecture for Capabilities-Based Planning, Mission-System Analysis, and Transformation[M]. Natl Book Network. (2002)

8. K. W. YANG, Z. W. YANG, Y. J. TAN, et al. Review of the evaluation methods of equipment system of systems facing the contribution rate[J]. Systems Engineering and Electronics, (2019)

9. C. K. LUO, Y. X. CHEN, Y. M. ZHANG, et al. Evaluation of equipment contribution rate to systemrof-systems based on hybrid parameter evidential network[J]. Acta Armamentarii, (2018)

10. J. L. Liang, W. Xiong. Overview of evaluation method of contribution of weapon equipment system[J]. Journal of Ordnance Equipment Engineering, 2018, 39(4): 67-71

11. X. W. CHEN, M. L. XIE, J. Q. ZHANG, Analysis on the contribution mechanism of new equipment system to the warfighting system[J]. Journal of Equipment Academy, (2016) 